\title{
Challenges, consequences, and lessons for way-outs to emergencies at hospitals: a systematic review study
}

\author{
Hamid Reza Rasouli ${ }^{*}$, Ali Aliakbar Esfahani ${ }^{2}$ and Mohsen Abbasi Farajzadeh²
}

\begin{abstract}
Background: Emergency Department (ED) overcrowding adversely affects patients' health, accessibility, and quality of healthcare systems for communities. Several studies have addressed this issue. This study aimed to conduct a systematic review study concerning challenges, lessons and way outs of clinical emergencies at hospitals.

Methods: Original research articles on crowding of emergencies at hospitals published from 1st January 2007, and 1st August 2018 were utilized. Relevant studies from the PubMed and EMBASE databases were assessed using suitable keywords. Two reviewers independently screened the titles, abstracts and the methodological validity of the records using data extraction format before their inclusion in the final review. Discussions with the senior faculty member were used to resolve any disagreements among the reviewers during the assessment phase.

Results: Out of the total 117 articles in the final record, we excluded 11 of them because of poor quality. Thus, this systematic review synthesized the reports of 106 original articles. Overall 14, 55 and 29 of the reviewed refer to causes, effects, and solutions of ED crowding, respectively. The review also included four articles on both causes and effects and another four on causes and solutions. Multiple individual patients and healthcare system related challenges, experiences and responses to crowding and its consequences are comprehensively synthesized.

Conclusion: ED overcrowding is a multi-facet issue which affects by patient-related factors and emergency service delivery. Crowding of the EDs adversely affected individual patients, healthcare delivery systems and communities. The identified issues concern organizational managers, leadership, and operational level actions to reduce crowding and improve emergency healthcare outcomes efficiently.
\end{abstract}

Keywords: Emergency department, Emergency crowding, Overcrowding

\section{Introduction}

The requirement of emergency healthcare service for people is an ongoing problem [1-5]. The ED must provide emergency care to the large populations. Nevertheless, the safe-networking of the emergency care added to the complexity of the role because the ED should provide services to the users regardless of their insurance and socioeconomic status [1,2]. Furthermore, the ED might be the only reference of health care services to people, particularly in rural areas $[1,2]$.

\footnotetext{
* Correspondence: hr.rasouli64@gmail.com

${ }^{1}$ Trauma Research Center, Baqiyatallah University of Medical Sciences, Tehran, Iran

Full list of author information is available at the end of the article
}

Studies demonstrated increasing emergency healthcare services use due to the raised accidental injuries. Nonetheless, the potentials for emergency healthcare systems have not been completely developed [3-5]. This situation generates the crowding and overcrowding of the EDs which in turn posed a reduction of quality healthcare services and results. Thus, crowding is a condition when demand for emergency healthcare services exceeds from the available resources $[3,6]$.

Overcrowding of the emergency healthcare services has adverse results to the patients, the healthcare services and the population $[7,8]$. Delay in healthcare services provided to patients can hurt the quality of the emergency services and also their outcomes [9]. Overcrowding of the ED could also generate the adverse

(c) The Author(s). 2019 Open Access This article is distributed under the terms of the Creative Commons Attribution 4.0 International License (http://creativecommons.org/licenses/by/4.0/), which permits unrestricted use, distribution, and reproduction in any medium, provided you give appropriate credit to the original author(s) and the source, provide a link to the Creative Commons license, and indicate if changes were made. The Creative Commons Public Domain Dedication waiver (http://creativecommons.org/publicdomain/zero/1.0/) applies to the data made available in this article, unless otherwise stated. 
consequences of standards services preparation, which in turn might outcomes in patients way out the EDs without obtaining the needed aids [7-9]. Despite the contributions to the understanding of medical emergencies $[10,11]$. This systematic review aimed to assess the causes and challenges of ED crowding, the experiences of emergency patients, emergency care providers, and healthcare systems, and the solutions to ED crowding and their consequences since 2007 globally. The outcomes are expected to contribute inputs to decisionmakers to contextualize practical solutions to promote the quality of medical emergency services and to the scientific readership.

\section{Materials and methods}

\section{Search strategy}

In this study, the definition for "crowding" from the American College of Emergency Physicians which states
"Crowding occurs when the identified need for emergency services exceeds available resources for patient care in the emergency department, hospital, or both" was used. Then, articles related to crowding in EDs published in English between January 1, 2007, and August 1, 2018, from the MEDLINE through PubMed and Embase electronic databases were searched. Search keywords and phrases utilized were: 'emergency', 'emergency medicine', 'pediatric emergency medicine', 'emergency medical services', 'emergency room', 'hospital emergency services', 'emergency health services', 'emergency department', 'emergency ward', 'EW', 'ED', "AND", 'crowding', 'overcrowded', 'crowded' 'overcrowding', 'divert', 'diversion', 'congestion', 'surged', 'surging', 'capacity', 'crises', 'crisis', 'occupancy', 'hospital bed utilization', 'bed', 'utilization', “OR”, "AND”, 'effects', 'consequences', 'outcomes',, affects', 'harm', 'impact', 'mortality', 'challenges', 'causes' 'strategies', 'solutions', 'lessons', 'interventions', 'negative'.

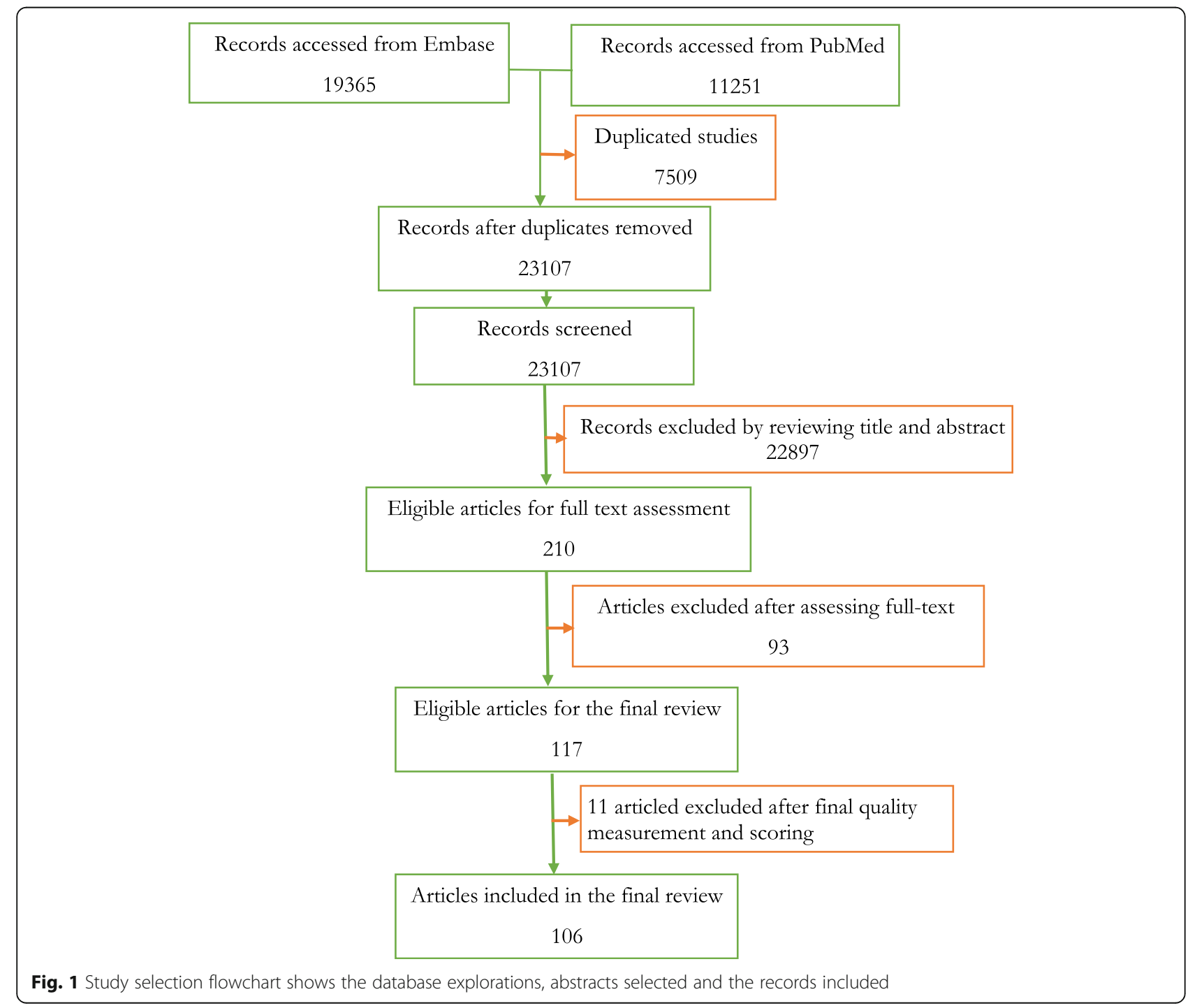




\section{Data collection and quality assessment}

Two reviewers (HRR AND MAF) independently screened the titles, abstracts and the methodological validity of the records using data extraction format before their inclusion in the final review. Discussions with the senior faculty member (AAE) were used to resolve any disagreements among the reviewers during the assessment phase. A total of 117 articles were eligible for the review (Fig. 1). The studies using the standardized Critical Appraisal Skills Programme (CASP) for the Cohort Studies [12], Qualitative Studies [13], and Systematic Reviews [14] were evaluated. Moreover, the Joanna Briggs Institute Meta-Analysis of Statistics Assessment and Review Instrument for studies which employed other designs was utilized [15]. Finally, 11 studies with an eligibility evaluation score of fewer than 0.33 points $(<33 \%)$, the final review was based on 106 studies.

The methodology part of the eligible articles was further assessed using the $\mathrm{R}$ 'wordcloud' software package to gain insight into the keywords in the abstracts [16]. We identified the focus of the studies and categorized the articles into those related to causes, effects, and solutions of crowding, and some form of their combinations.

\section{Results}

Out of the total 106 eligible peer-reviewed original articles included in the final review, 14, 55, and 29 of them were on causes, effects, and solution of/to crowding of the ED, respectively. The articles reported on causes and effects were four [3, 17-19], and the remaining were on causes and solutions to crowding [9, 20-22] of/to crowding. Further assessment of the abstracts of the final articles using the R 'wordcloud' software package indicated some of the keywords and their frequencies (Fig. 2).

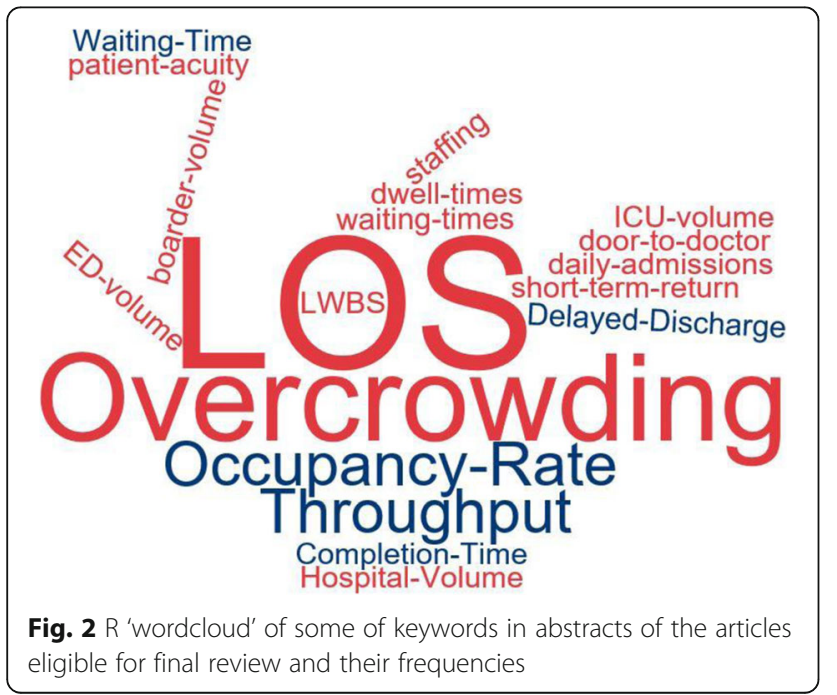

\section{Causes of EDs crowding}

Studies reported different factors affecting the EDs crowding. Table 1 presented the individual patients, inputs (both human and material) and the service delivery processes related factors that influenced crowding either directly or indirectly. Male gender, being young $(<18$ years) [18], and old age [23, 24, 35] were a patientrelated factor associated with EDs crowding. The lifestyle of the emergency patient such as alcoholism also led a frequent hospital visit and crowding [25].

The high number of emergency patients and the seriousness of their conditions have hindered the timely admissions of the emergency patients and led to EDs overcrowding [3]. The increased waiting or boarding time of patients in the ED, the delay in discharging of the admitted patients $[8,26]$, and the high non-urgent patient flow to the hospitals $[17,19]$ were other identified factors that contributed to the EDs crowding. Furthermore, the delay in diagnostics and diagnostic test result reports $[19,24,27,31]$ and the delay in initiating treatment to emergency patients [32] were among the emergency service delivery related factors associated

Table 1 Leading causes of EDs crowding

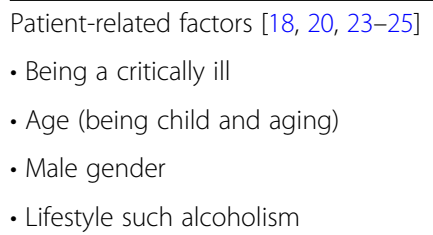

- Long waiting of emergency patients for diagnostic test results

b) Emergency department staff related causes [22, 25, 27, 28, 31-34]

- Wrong diagnosis

- Delay of consultants

- Delay of staff to provide emergency services

- Delay in transferring patients to inpatient ward

- Shortage of emergency care providers

c) Premises and materials of ED-related factors $[9,27]$

- Shortage of beds for admitting emergency patients

Other hospital services delivery related causes $[3,19,22,27,29,31]$

- Delay in laboratory and imaging investigations

- Delay in diagnostic test results/reports

- The high number of patients in the waiting room of a hospital

- The reluctance of hospital staff to admit patients from ED 
with the increased the length of patients waiting time that resulted in EDs crowding. The slow or delayed emergency patient admission process to the ED and inpatient wards [22, 33], and the prolonged laboratory and radiology testing influenced the crowding [22]. Shortage of emergency care staffs $[22,28]$ and hospital beds for admission of emergency patients [9, 27], and the reluctance of hospital staff to admit the emergency [29] were identified contributors to the EDs crowding.

\section{Effects of EDs crowding}

The outcomes of overcrowding of ED are multilevel including effect on patients' health consequences, healthcare delivery system and the communities. Table 2 shows the mainly related outcomes of the ED overcrowding. ED overcrowding caused delay treatment to patients and subsequently increased risks of not being precisely examined by the healthcare workers $[19,32,36-40]$. The patients through many walkouts may react to delay healthcare services and the overcrowding [41]. These situations could have an adverse effect of patients' disease [50] and subsequently another consequences including re-admissions [51, 62], hospitalizations [50, 52, 53], healthcare costs [54], patients' satisfaction [42-45], medical malpractices, morbidity [46-49], and patients' mortality [50-61].

The discharging of patients especially with high-risk clinical characteristics [51] and misleading the patients to other departments [18] have adversely impacted the patients' health consequences. These situations could increase the time of accepting and transferring the outpatients [79] and increase patient's admission and re-admission rates [42, 61, 64, 89] consequently a reduced discharging

Table 2 Adverse consequences of EDs crowding

\footnotetext{
Adverse consequences on patients

- Increase delay to treatment, patients LWBS [19, 32, 36-40] and subsequently walkouts due to perceived ED LOS [41]

- Increase dissatisfaction [42-45] and medical malpractice [46-49]

- Increase adverse effect [50] and deaths [50-61]

- Increase readmissions [51, 62], hospitalization [50,52,53] and costs for healthcare [54]

Adverse consequences on healthcare delivery system

- Increase workload [63], delay service provision/decision making and increased ED LOS [53, 54, 56, 60, 61, 63-78]

- Increase delay to management of outpatients [79] and overuse of ED facilities [64]

- Decrease efficiency, and increase costs of healthcare $[17,36,40,50,61$, 80, 81]

- Decrease consideration for infection prevention and control measures [82]

- Decrease time and precise to examination patients' conditions [71], compliance to standardization of healthcare [52] and quality of healthcare [39, 42, 63, 83-87]

- Discharging of patients with high-risk clinical features [51] and diverting of patients to proper facilities [18]

- Increase patients readmission rate [42] and admission rate to hospital wards [64]

Decrease discharging rate of patients $[37,51,57,59,66,79,88]$ and admission of patients [89]
}

rate of patients [51]. The increased hospitalization of patients caused overuse of all facilities [64].

The high workload caused prolonged service preparation and clinical decision making and raised patients' LOS [53, 54, 56, 60, 61, 63-78]. These conditions have adversely affected the quality of services and performance $[17,36,40,50,61,80,81,83]$.

\section{Solutions to ED crowding}

Medical emergencies and their negative consequences were of concern and several studies identified or suggested different approaches (strategies, and tactics), and solutions to reduces or prevent ED crowding and related consequences. The approaches can be broadly categorized into the organization or management level and operation level interventions (Table 3).

\section{Organization/management level solutions}

Involving the executive leadership, implementing of hospital-wide coordinated strategies, strengthening evidence-based management and performance accountability [90] were suggested solutions to reduce the LOS of patients at EDs. Other approaches for reducing the ED crowding included implementing a coordinated patient transfer networking system (RTNS) [91] and an independent capacity protocol [93, 94]. Furthermore, the application of lean principles/Six Sigma in service delivery [92], and forecasting ED crowding [95] were strategies to shorten patient discharging and boarding hours.

\section{Operational level solutions}

Several studies recommended or identified interventions involving the clinical staff, operational level strategies and tactics, service delivery processes, healthcare infrastructure, and other services related factors that contributed or would contribute to the solution of ED crowding and its negative aftermaths.

\section{a. Staffing the ED and motivating the staffs:} Introducing the pay for performance mechanism [96] and assigning ED residents [97] can contribute to the reduction of LOS of patients. Thus, the allocation of residents at the ED not only reduces the waiting time but also reduces the number of patients LWBS [98].

b. Operational level strategies and tactics: Studies identified several operational-level means to reduce or prevent ED crowding. The methods included evidence-based patient admission [21], the application of a Discrete Event Simulation (DES) model [22], improving the emergency patient flow coordination leadership [101], introducing a Stat Lab within the ED [105], and implementing specific hospital-level action plans (Code Help Regulation) [106]. The use 
Table 3 Solutions of EDs crowding

Organization or management level solutions

- Executive leadership involvement, hospital-wide coordinated strategies, data-driven management, and performance accountability [90]

- Implementing emergency patient transfer network system (RTNS) [91]

- Implementing Lean/Six Sigma Method [92]

- Implementing an independent capacity protocol [93, 94]

- Forecasting ED crowding [95]

Operational level solutions

a. Staffing and motivation

- Pay for performance [96]

- Staffing ED with qualified professionals [97, 98]

b. Operational level strategies and tactics

- Developing evidence-based admission criteria [21]

- Implementing Electronic Blockage System (EBS) [99]

- Implementing smoothing strategy [100]

- Using capacity alert escalation calls [20]

- Applying Discrete Event Simulation (DES) model [22]

- Improving leadership of ED [101]

- Implementing contingency strategy [102]

- Using management-support multimodal hospital-wide interventions [103]

- Implementing four-hour-rule for emergency care [104]

- Introducing of Stat Lab [105]

- Implementing Code Help Regulation [106]

- Using a dashboard to provide real-time information about crowding [107]

c. Service delivery process

- Acute care emergency surgery service provision [108]

-Whole week emergency service delivery [109]

- Implementing triage by physicians [110]

- Introducing efficient patient discharging process [111]

- High-turnover utility bed management [112]

- Implementing Timely Quality Care [113]

- Implementing an improved ED patient flow [114]

d. Other services

- Enhanced primary care $[21,115]$

- Optimizing translation services [21]

e. Premises

- Expanding or opening additional EDs $[116,117]$

- Hallway emergency bed [9]

- Increasing hospital bed capacity [118]

of Electronic Blockage System (EBS) (a form of triage system) contributed to the reduction of the ED crowding and the facilitation of patients admissions [99].

The application of management-support multimodal hospital-wide interventions decreases the ED occupancy and increase the four-hour performance without compromising the quality of care [103]. Following the four-hour-rule in deciding for admitting or discharging of patients also reduces patient death [104]. Furthermore, properly utilizing the unused capacity (smoothing strategy) [100], and using the capacity alert escalation calls [20] contribute to the reduction of the ED crowding by lowering ED bed occupancy rates. Assessing the patients in the waiting room was a feasible approach to reduce the ED crowding [102]. Besides, the use a dashboard provides real-time information which leads to actions towards preventing crowding [107].

c. Service delivery process: Some interventions focused on emergency service delivery can reduce crowding. For example, initiating an acute care emergency surgery service, improving the ED patient flow and introducing an efficient patient discharging process reduce the ED bed occupancy and LOS $[108,111,114]$. The high-turnover utility bed management can also decrease ambulance diversion hours and LOS of patients [112]. The practice of triage by physicians reduce the patients LWBS in the EDs [110]. Other interventions which contribute to the reduction of crowding included whole week emergency service delivery [109] and implementing Timely Quality Care [113].

d. Other services: Improving other services such as enhancing primary care $[21,115]$, optimizing translation services concerning patients' issues [21] and an engagement on specialists in the outpatient environment $[116,117]$ contribute to the reduction of ED LOS and crowding.

e. Premises: The high emergency patient flow forced the healthcare delivery system to address related issues. Expanding or opening additional EDs were suggested to reduce patients LWBS and boarding hours $[116,117]$. Others followed hallway emergency bed policy [9] and increasing hospital bed capacity [118] to reduce waiting time and ED crowding.

\section{Discussion}

Patients in the extreme the age categories (being a child and the elderly) $[18,23-25,35]$, might have contributed to the crowding due to reduced physical mobility and the involvement of their relatives and the different emergency care expertise in their care. Among other personal factors, alcoholic patients who present to the ED [25] might also have limited mobility or might be unable to provide self-care. Being a male patient was also associated with frequent ED visits, while the exact relationship was not clear [18]. While a recent systematic review did not report concerning the relationship between Individual characteristics and crowding [119], our systematic review revealed an association between age and ED 
crowding. Nevertheless, being male, arriving of emergency patients during the weekends, and being adult non-trauma patients were reported to be linked with short LOS.

The seriousness of the emergency condition, the high flow of emergency patients, and the involvement of the different actors (relatives and health professionals) affect the service delivery process $[3,26-29,120]$. These conditions are more likely to cause a delay in emergency care provision [33], admitting and discharging of patients [26], and an increase in the waiting time of patients [120], in which all of them can lead to increased ED crowding. The high flow of in and out of the emergency patients including the inpatient boarding [10] and the presence of urgent and complex emergency conditions of the patients usually lead to crowding of the ED [120]. The prolonged LOS in EDs related to some causes [21] and the large volume of emergency patients flow to the ED are a common reason for crowding.

Several healthcare providers related factor including wrong diagnosis, delay in consultants to see emergency patients, delay in services provision and transferring of patients to inpatient wards, and a shortage of emergency healthcare providers $[22,25,27,28,31-34]$ contributed to the ED crowding. Other previous systematic reviews also identified inadequate staffing including the shortage of emergency care nursing staff and delays in clinical decisions as causes of ED crowding $[10,11]$.

The inadequacy of beds at the ED for admitting patients was health infrastructure related causes of crowding $[9,27]$. Similarly, other systematic reviews also identified the shortage of beds to be associated with ED crowding $[10,11]$. The high flow of emergency patients to the ED who may require admissions and the limited number of beds in the ED leads to crowding and poor healthcare outcomes.

The delay in laboratory investigations, diagnostic imaging and in reporting diagnostic test results contribute to ED crowding [24, 27]. The shortage of materials and other resources can lead to delay in laboratory test results [31]. The high number of emergency patients [19], the reluctance of the hospital staff to admit emergency patients [29] and the inadequate number of emergency patient admissions $[10,11]$ were also reasons for crowding.

The results showed ED overcrowding related to delay treatment and increased risks not being seen for patients $[19,32,36-40]$. These conditions have an adverse effect of their disease [50], readmissions [51, 62], hospitalizations [50, 52, 53], healthcare costs [54], patients' satisfaction [42-45]. In a systematic review by Morley et al. (2018) showed prolonged patient evaluation and preparation of care could adversely affect death rate, medical malpractice and patient satisfaction [11]. Also, in another systematic review study (2008) showed EDs overcrowding negatively affected patients' mortality, quality of healthcare, and costs of services [10].

Our results demonstrated that ED overcrowding negatively effects on patients' health, healthcare delivery services and the communities [42-49, 52-61, 64, 79, 89]. The high workload caused prolonged healthcare services and clinical decision making and raised patients' LOS $[53,54,56,60,61,63-78]$. Several emergency healthcare systems associated outcomes evaluated by Morley et al. study (2018) for chiefly they concentrated on inpatient LOS and ED LOS [11].

The involvement of the executive leaders, the use of hospital-wide coordinated approaches, and evidence-based management and performance accountability were some of the strategies implemented to reduce ED crowding and its consequences [90]. The use of a coordinated emergency patient transfer network system [91], and an independent capacity protocol $[93,94]$ were as strategies for reducing ED LOS of patients. Furthermore, the lean principles/Six Sigma Method in service delivery [92] and forecasting of ED crowding [95] believed to shorten patient discharging and boarding hours. Another systematic review study also identified leadership program/support and alternative admission policies as solutions to crowding [11].

Several specific technical (front-line) level tools or solutions have been identified. The staffing of the ED with qualified professionals [98] and the use of motivational mechanisms such as pay for performance [96] contributed to the alleviation of ED crowding. Developing and using evidence-based admission criteria [21], implementing Electronic Blockage System [99] and smoothing strategy [100], using capacity alert escalation calls [20] and applying Discrete Event Simulation (DES) model [22] were also the tactics applied to facilitate emergency service delivery and reduce crowding. Improving leadership of the ED [101], evaluating emergency patients in the waiting room as a contingency strategy [102], and using management-support multimodal hospital-wide interventions [103] were other reported tactics. Furthermore, implementing four-hour-rule for emergency care [104], introducing Stat Lab [105], implementing Code Help Regulation [106] and Using a dashboard to provide real-time information about crowding [107] were proposed operational tactics to the reduce ED crowding and related consequences.

Studies identified several technical level (or front-line) measures or solutions targeting the alleviation of ED crowding. Staffing the ED with qualified professionals [98] and pay for performance [96] were among others. Other tactics which aimed to to facilitate emergency service delivery and reduce crowding included: developing and using evidence-based admission criteria [21], implementing Electronic Blockage System [99], and smoothing strategy [100], using capacity alert escalation calls [20] 
and applying Discrete Event Simulation (DES) model [22]. Improving leadership of the ED [101], evaluating emergency patients in the waiting room as a contingency strategy [102], and using management-support multimodal hospital-wide interventions [103] were other reported tactics. Furthermore, implementing four-hourrule for emergency care [104], introducing Stat Lab [105], implementing Code Help Regulation [106] and Using a dashboard to provide real-time information about crowding [107] were proposed operational level tactics to the reduce ED crowding and related consequences.

Operational interventions targeting the service delivery processes were also identified. Initiating an acute care emergency surgery service, improving ED patient flow and introducing an efficient patient discharging process could reduce the ED bed occupancy rate and LOS [108, $111,114]$. The high-turnover utility bed management [112], the practice of triage by physicians [110], whole week emergency service delivery [109], and implementing Timely Quality Care [113] contributed to the improvements in service delivery and reduction of crowding. A recent systematic review also identified different crowding measure, social interventions, fast track, ED nurse flow coordinator as operational level solutions to ED crowding [11].

Initiating an acute care emergency surgery service, improving ED patient flow, and introducing an efficient patient discharging process $[108,111,114]$ were recommended interventions targeting improvement in service delivery processes and reduction in ED bed occupancy rate and LOS. High-turnover utility bed management [112], practicing triage by physicians [110], whole week emergency service delivery [109], and implementing Timely Quality Care [113] were also frontline interventions that contribute to improved service delivery and reduced crowding. A recent systematic review also identified different crowding measure, social interventions, fast track, and ED nurse flow coordinator as operational level solutions to ED crowding [11].

The emergency care service provision should be accommodating. Some studies suggested enhancing primary care as a means of reducing the ED crowding [21, 115], while another study proposed the optimization of translation services to reduce crowding [21]. Others recommended premises related interventions such as expanding or opening an additional ED [116, 117], hallway emergency bed [9] and increasing hospital bed capacity [118] as a solution to prevent crowding.

The emergency healthcare service provision should meet the needs of the patients. Some studies suggested enhancing primary care as a means of reducing ED crowding [21, 115], while another study proposed the optimization of translation services to reduce crowding [21]. Other suggestions were premises related interventions such as expanding or opening additional ED [116, 117], hallway emergency bed [9] and increasing hospital bed capacity [118] as a solution to prevent crowding. Some studies showed reporting of ED utilization to a pediatric specialist was correlated with a cultural and method development to preferentially manage patients with essential matters in the office $[119,120]$.

\section{Strengths and limitation}

This study attempted to characterize the details of the challenges, emergency patients and emergency clinical staff reactions to clinical emergencies, and the strategies and tactics followed by healthcare service organizations and front-line staff to tackle ED crowding and related issues. Comprehensive keywords and terms to cover all relevant published studies on ED crowding from the PubMed and Embase databases were utilized. The qualities of the studies were evaluated by appropriate checklists and excluded those with low-level quality. However, the systematic review study was limited to studies published only in the English language. The included original studies did not utilize a unique definition for EDs crowding measurement, which led to the inclusion of all ED crowding-related information in the synthesis.

\section{Conclusions}

ED overcrowding is a multi-facet issue which affects by patient-related factors and emergency service delivery. Crowding of the EDs adversely affected individual patients, healthcare delivery systems and communities. The identified issues concern organizational managers, leadership, and operational level actions to reduce crowding and improve emergency healthcare outcomes efficiently. This systematic review study showed the importance of the integrated response to emergencies and emergency related overcrowding and consequences to better address the healthcare needs of emergency patients and effectiveness of healthcare service delivery facilities. Also, multiple health service organization and operational level responses to emergency-related crowding and their consequences were identified.

\section{Abbreviations Headings \\ Acknowledgements \\ Not applicable}

CASP: Critical Appraisal Skills Programme; ED: Emergency Department; LOS: Length of Stay; LWBS: Left without Being Seen; MeSH: Medical Subject

\section{Authors' contributions}

All the authors (HRR, AAE, and MAF) have contributed to the construction of the concepts, data gathering, data analysis, preparation of the final manuscript and all authors have read and approved the manuscript.

\section{Funding}

Not applicable

Availability of data and materials

The datasets used and/or analyzed during the current study are available from the corresponding author on reasonable request. 


\section{Ethics approval and consent to participate}

The research protocol was approved by the review committee of the Baqiyatallah University of Medical Sciences. It did not involve data collection at individual level or human subjects.

\section{Consent for publication}

Not applicable

\section{Competing interests}

The authors declare that they have no competing interests.

\section{Author details}

${ }^{1}$ Trauma Research Center, Baqiyatallah University of Medical Sciences, Tehran, Iran. ${ }^{2}$ Marine Medicine Research Center, Baqiyatallah University of Medical Sciences, Tehran, Iran.

Received: 8 January 2019 Accepted: 9 October 2019

Published online: 30 October 2019

\section{References}

1. Higginson I. Emergency department crowding. Emerg Med J. 2012;29(6): 437-43.

2. Derlet RW, Richards JR. Ten solutions for emergency department crowding. West J Emerg Med. 2008;9(1):24.

3. Makama JG, Iribhogbe $P$, Ameh EA. Overcrowding of accident \& emergency units: is it a growing concern in Nigeria? Afr Health Sci. 2015;15(2):457-65.

4. Rathlev NK, Chessare J, Olshaker J, Obendorfer D, Mehta SD, Rothenhaus T, et al. Time series analysis of variables associated with daily mean emergency department length of stay. Ann Emerg Med. 2007:49(3):265-71.

5. Yarmohammadian MH, Rezaei F, Haghshenas A, Tavakoli N. Overcrowding in emergency departments: a review of strategies to decrease future challenges. J Res Med Sci. 2017;22:1-9.

6. Iraqi IJ, Mahmoudi H. Causes and consequences of emergency department overcrowding. Methods Resolving Health Res. 2016;1(4):239-44.

7. Bernstein SL, Aronsky D, Duseja R, Epstein S, Handel D, Hwang U, et al. The effect of emergency department crowding on clinically oriented outcomes. Acad Emerg Med. 2009;16(1):1-10.

8. Henneman PL, Nathanson BH, Li H, Smithline HA, Blank FSJ, Santoro JP, et al. Emergency department patients who stay more than 6 hours contribute to crowding. J Emerg Med. 2010;39(1):105-12.

9. Hillier DF, Parry GJ, Shannon MW, Stack AM. The effect of hospital bed occupancy on throughput in the pediatric emergency department. Ann Emerg Med. 2009;53(6):767-76 e3.

10. Hoot NR, DJAoem A. Systematic review of emergency department crowding: causes, effects, and solutions. Annals of emergency medicine. 2008;52(2):126-36 e1.

11. Morley C, Unwin M, Peterson GM, Stankovich J, LJPo K. Emergency department crowding: A systematic review of causes, consequences and solutions. PloS one. 2018;13(8):e0203316.

12. Critical Appraisal Skills Programme. CASP (Cohort Study) Checklist. [online] Available at: https://casp-uk.net/wp-content/uploads/2018/01/CASP-CohortStudy-Checklist_2018.pdf. Accessed 2018.

13. Critical Appraisal Skills Programme. CASP (Qualitative) Checklist. [online] Available at: https://casp-uk.net/wp-content/uploads/2018/01/CASPQualitative-Checklist-2018.pdf . Accessed 2018.

14. Critical Appraisal Skills Programme. CASP (Systematic Review) Checklist. [online] Available at: https://casp-uk.net/wp-content/uploads/2018/01/ CASP-Systematic-Review-Checklist_2018.pdf . Accessed 2018.

15. http://joannabriggs.org/research/critical-appraisal-tools.html. Accessed 2017.

16. Fellows I, Fellows MI, Rcpp L, Rcpp L. Package 'wordcloud'; 2018.

17. Cremonesi $P$, di Bella $E$, Montefiori M, Persico L. The robustness and effectiveness of the triage system at times of overcrowding and the extra costs due to inappropriate use of emergency departments. Appl Health Econ Health Policy. 2015;13(5):507-14.

18. Shenoi RP, Ma L, Jones J, Frost M, Seo M, Begley CE. Ambulance diversion as a proxy for emergency department crowding: the effect on pediatric mortality in a metropolitan area. Acad Emerg Med. 2009;16(2):116-23.

19. Wang H, Robinson RD, Cowden CD, Gorman VA, Cook CD, Gicheru EK, et al. Use of the SONET score to evaluate urgent care center overcrowding: a prospective pilot study. BMJ Open. 2015;5(4):e006860.
20. Khanna S, Boyle J, Zeitz K. Using capacity alert calls to reduce overcrowding in a major public hospital. Aust Health Rev. 2014;38(3):318-24.

21. Mansbach JM, Clark S, Barcega BR, Haddad H, Camargo CA Jr. Factors associated with longer emergency department length of stay for children with bronchiolitis : a prospective multicenter study. Pediatr Emerg Care. 2009;25(10):636-41.

22. Paul JA, Lin L. Models for improving patient throughput and waiting at hospital emergency departments. J Emerg Med. 2012;43(6):1119-26.

23. Knapman M, Bonner A. Overcrowding in medium-volume emergency departments: effects of aged patients in emergency departments on wait times for non-emergent triage-level patients. Int J Nurs Pract. 2010;16(3):310-7.

24. Vegting IL, Alam N, Ghanes K, Jouini O, Mulder F, Vreeburg M, et al. What are we waiting for? Factors influencing completion times in an academic and peripheral emergency department. Neth J Med. 2015;73(7):331-40.

25. Verelst S, Pierloot S, Desruelles D, Gillet JB, Bergs J. Short-term unscheduled return visits of adult patients to the emergency department. J Emerg Med. 2014;47(2):131-9.

26. Mustafa F, Gilligan P, Obu D, O'Kelly P, O'Hea E, Lloyd C, et al. 'Delayed discharges and boarders': a 2-year study of the relationship between patients experiencing delayed discharges from an acute hospital and boarding of admitted patients in a crowded ED. Emerg Med J. 2016; 33(9):636-40.

27. Erenler AK, Akbulut S, Guzel M, Cetinkaya H, Karaca A, Turkoz B, et al. Reasons for overcrowding in the emergency department: experiences and suggestions of an education and research hospital. Turkiye Acil Tip Dergisi. 2014;14(2):59-63.

28. Cha WC, Ahn KO. Emergency department crowding disparity: a Nationwide cross-sectional study. J Korean Med Sci. 2016;31(8):1331-6.

29. Ye L, Zhou G, He X, Shen W, Gan J, Zhang M. Prolonged length of stay in the emergency department in high-acuity patients at a Chinese tertiary hospital. Emerg Med Australas. 2012;24(6):634-40.

30. Lucas R, Farley H, Twanmoh J, Urumov A, Olsen N, Evans B, et al. Emergency department patient flow: the influence of hospital census variables on emergency department length of stay. Acad Emerg Med. 2009; 16(7):597-602.

31. Habib MI, Khan KM. Overcrowding and possible solutions for a busy paediatric emergency department. J Pak Med Assoc. 2017;67(9):1398-403.

32. Fee C, Weber EJ, Maak CA, Bacchetti P. Effect of Emergency Department Crowding on Time to Antibiotics in Patients Admitted With CommunityAcquired Pneumonia. Ann Emerg Med. 2007;50(5):501-9 e1.

33. Stang AS, McGillivray D, Bhatt M, Colacone A, Soucy N, Léger R, et al. Markers of overcrowding in a pediatric emergency department. Acad Emerg Med. 2010;17(2):151-6.

34. Bullard MJ, Villa-Roel C, Bond K, Vester M, Holroyd BR, Rowe BH. Tracking emergency department overcrowding in a tertiary care academic institution. Healthc Q. 2009;12(3):99-106.

35. Kawano $T$, Nishiyama K, Anan H, Tujimura Y. Direct relationship between aging and overcrowding in the ED, and a calculation formula for demand projection: a cross-sectional study. Emerg Med J. 2014;31(1):19-23.

36. Depinet HE, lyer SB, Hornung R, Timm NL, Byczkowski TL. The effect of emergency department crowding on reassessment of children with critically abnormal vital signs. Acad Emerg Med. 2014:21(10):1116-20.

37. Gaieski DF, Agarwal AK, Mikkelsen ME, Drumheller B, Cham Sante S, Shofer FS, et al. The impact of ED crowding on early interventions and mortality in patients with severe sepsis. Am J Emerg Med. 2017;35(7):953-60.

38. Wiler UL, Bolandifar E, Griffey RT, Poirier RF, Olsen T. An emergency department patient flow model based on queueing theory principles. Acad Emerg Med. 2013;20(9):939-46.

39. Pines JM, Hollander JE. Emergency department crowding is associated with poor Care for Patients with Severe Pain. Ann Emerg Med. 2008;51(1):1-5.

40. Reznek MA, Murray E, Youngren MN, Durham NT, Michael SS. Door-toimaging time for acute stroke patients is adversely affected by emergency department crowding. Stroke. 2017;48(1):49-54.

41. van der Linden MC, Lindeboom R, van der Linden N, van den Brand CL, Lam RC, Lucas C, et al. Walkouts from the emergency department: characteristics, reasons and medical care needs. Eur J Emerg Med. 2014; 21(5):354-9.

42. Mullins PM, Pines JM. National ED crowding and hospital quality: results from the 2013 hospital compare data. Am J Emerg Med. 2014;32(6):634-9.

43. Pines JM, Iyer S, Disbot M, Hollander JE, Shofer FS, Datner EM. The effect of emergency department crowding on patient satisfaction for admitted patients. Acad Emerg Med. 2008;15(9):825-31. 
44. Tekwani KL, Kerem Y, Mistry CD, Sayger BM, Kulstad EB. Emergency department crowding is associated with reduced satisfaction scores in patients discharged from the emergency department. West J Emerg Med. 2013;14(1):11-5.

45. Wang H, Ojha RP, Robinson RD, Jackson BE, Shaikh SA, Cowden CD, et al. Optimal Measurement Interval for Emergency Department Crowding Estimation Tools. Ann Emerg Med. 2017;70(5):632-9 e4.

46. Dubin J, Blumenthal J, Milzman D. Emergency department crowding and physician inexperience are synergistically associated with increased physician errors. Ann Emerg Med. 2013;62(4):S49.

47. Epstein SK, Huckins DS, Liu SW, Pallin DJ, Sullivan AF, Lipton RI, et al. Emergency department crowding and risk of preventable medical errors. Intern Emerg Med. 2012;7(2):173-80.

48. Kulstad EB, Sikka R, Sweis RT, Kelley KM, Rzechula KH. ED overcrowding is associated with an increased frequency of medication errors. Am J Emerg Med. 2010;28(3):304-9

49. Pines JM, Pollack CV Jr, Diercks DB, Chang AM, Shofer FS, Hollander JE. The association between emergency department crowding and adverse cardiovascular outcomes in patients with chest pain. Acad Emerg Med. 2009;16(7):617-25

50. Verelst S, Wouters P, Gillet JB, Van Den Berghe G. Emergency department crowding in relation to in-hospital adverse medical events: a large prospective observational cohort study. J Emerg Med. 2015;49(6):949-61.

51. Ben-Yakov M, Kapral MK, Fang J, Li S, Vermeulen MJ, Schull MJ. The association between emergency department crowding and the disposition of patients with transient ischemic attack or minor stroke. Acad Emerg Med. 2015;22(10):1145-54

52. Shin TG, Jo IJ, Choi DJ, Kang MJ, Jeon K, Suh GY, et al. The adverse effect of emergency department crowding on compliance with the resuscitation bundle in the management of severe sepsis and septic shock. Crit Care. 2013;17(5):1-11.

53. Cha WC, Shin SD, Cho JS, Song KJ, Singer AJ, Kwak YH. The association between crowding and mortality in admitted pediatric patients from mixed adult-pediatric emergency departments in Korea. Pediatr Emerg Care. 2011; 27(12):1136-41.

54. Sun $B C$, Hsia RY, Weiss RE, Zingmond D, Liang $L$, Han W, et al. Effect of emergency department crowding on outcomes of admitted patients. Ann Emerg Med. 2013;61(6):605-11 e6.

55. Derose SF, Gabayan GZ, Chiu VY, Yiu SC, Sun BC. Emergency department crowding predicts admission length-of-stay but not mortality in a large health system. Med Care. 2014;52(7):602-11.

56. Hong KJ, Shin SD, Song KJ, Cha WC, Cho JS. Association between ED crowding and delay in resuscitation effort. Am J Emerg Med. 2013;31(3):509-15.

57. Jo S, Jeong $T$, Jin YH, Lee JB, Yoon J, Park B. ED crowding is associated with inpatient mortality among critically ill patients admitted via the ED: post hoc analysis from a retrospective study. Am J Emerg Med. 2015;33(12):1725-31.

58. Jo S, Jin YH, Lee JB, Jeong T, Yoon J, Park B. Emergency department occupancy ratio is associated with increased early mortality. J Emerg Med. 2014:46(2):241-9.

59. McCusker J, Vadeboncoeur A, Lévesque JF, Ciampi A, Belzile E. Increases in emergency department occupancy are associated with adverse 30-day outcomes. Acad Emerg Med. 2014;21(10):1092-100.

60. Van Der Linden N, Van Der Linden MC, Richards JR, Derlet RW, Grootendorst DC, Van Den Brand CL. Effects of emergency department crowding on the delivery of timely care in an inner-city hospital in the Netherlands. Eur J Emerg Med. 2016;23(5):337-43.

61. Wu D, Zhou X, Ye L, Gan J, Zhang M. Emergency department crowding and the performance of damage control resuscitation in Major trauma patients with hemorrhagic shock. Acad Emerg Med. 2015;22(8):915-21.

62. Hsia RY, Asch SM, Weiss RE, Zingmond D, Gabayan G, Liang LJ, et al. Is emergency department crowding associated with increased "bounceback" admissions? Med Care. 2013;51(11):1008-14

63. Fee C, Weber EJ, Bacchetti P, Maak CA. Effect of emergency department crowding on pneumonia admission care components. Am J Manag Care. 2011;17(4):269-78.

64. Chiu IM, Lin YR, Syue YJ, Kung CT, Wu KH, Li CJ. The influence of crowding on clinical practice in the emergency department. Am J Emerg Med. 2018; 36(1):56-60.

65. Gabayan GZ, Derose SF, Chiu WY, Yiu SC, Sarkisian CA, Jones JP, et al Emergency Department Crowding and Outcomes After Emergency Department Discharge. Ann Emerg Med. 2015;66(5):483-92 e5.
66. Graham J, Aitken ME, Shirm S. Correlation of measures of patient acuity with measures of crowding in a pediatric emergency department. Pediatr Emerg Care. 2011;27(8):706-9.

67. Hwang U, Richardson L, Livote E, Harris B, Spencer N, Sean MR. Emergency department crowding and decreased quality of pain care. Acad Emerg Med. 2008:15(12):1248-55.

68. Kennebeck SS, Timm NL, Kurowski EM, Byczkowski TL, Reeves SD. The association of emergency department crowding and time to antibiotics in febrile neonates. Acad Emerg Med. 2011;18(12):1380-5.

69. Kulstad EB, Kelley KM. Overcrowding is associated with delays in percutaneous coronary intervention for acute myocardial infarction. Int J Emerg Med. 2009;2(3):149-54.

70. Mills AM, Shofer FS, Chen EH, Hollander JE, Pines JM. The association between emergency department crowding and analgesia administration in acute abdominal pain patients. Acad Emerg Med. 2009;16(7):603-8.

71. O'Connor E, Gatien M, Weir C, Calder L. Evaluating the effect of emergency department crowding on triage destination. Int J Emerg Med. 2014;7(1):1-7.

72. Pines JM, Localio AR, Hollander JE, Baxt WG, Lee H, Phillips C, et al. The impact of emergency department crowding measures on time to antibiotics for patients with community-acquired pneumonia. Ann Emerg Med. 2007:50(5):510-6.

73. Pines JM, Prabhu A, Hilton JA, Hollander JE, Datner EM. The effect of emergency department crowding on length of stay and medication treatment times in discharged patients with acute asthma. Acad Emerg Med. 2010;17(8):834-9.

74. Sikka R, Mehta S, Kaucky C, Kulstad EB. ED crowding is associated with an increased time to pneumonia treatment. Am J Emerg Med. 2010;28(7):809-12.

75. van der Linden MC, Meester BE, van der Linden N. Emergency department crowding affects triage processes. Int emerg nurs. 2016;29:27-31.

76. McCarthy ML, Zeger SL, Ding R, Levin SR, Desmond JS, Lee J, et al. Crowding Delays Treatment and Lengthens Emergency Department Length of Stay, Even Among High-Acuity Patients. Ann Emerg Med. 2009;54(4): 492-503 e4.

77. Mills AM, Baumann BM, Chen EH, Zhang KY, Glaspey LJ, Hollander JE, et al. The impact of crowding on time until abdominal CT interpretation in emergency department patients with acute abdominal pain. Postgrad Med. 2010;122(1):75-81

78. Phillips JL, Jackson BE, Fagan EL, Arze SE, Major B, Zenarosa NR, et al. Overcrowding and its association with patient outcomes in a median-low volume emergency department. J Clin Med Res. 2017;9(11):911.

79. Ward MJ, Baker O, Schuur JD. Association of emergency department length of stay and crowding for patients with ST-elevation myocardial infarction. West J Emerg Med. 2015;16(7):1067-72.

80. Shenoi R, Ma L, Syblik D, Yusuf S. Emergency department crowding and analgesic delay in pediatric sickle cell pain crises. Pediatr Emerg Care. 2011; 27(10):911-7.

81. Medley DB, Morris JE, Stone CK. Crowding and physician practice: an association between emergency department crowding and rates of imaging studies ordered by physicians. Hong Kong J Emerg Med. 2010; 17(4):413.

82. Muller MP, Carter E, Siddiqui N, Larson E. Hand hygiene compliance in an emergency department: the effect of crowding. Acad Emerg Med. 2015; 22(10):1218-21.

83. Chang AM, Lin A, Fu R, McConnell KJ, Sun B. Associations of emergency department length of stay with publicly reported quality-of-care measures. Acad Emerg Med. 2017;24(2):246-50.

84. Lee CC, Lee NY, Chuang MC, Chen PL, Chang CM, Ko WC. The impact of overcrowding on the bacterial contamination of blood cultures in the ED. Am J Emerg Med. 2012;30(6):839-45.

85. Pines JM, Garson C, Baxt WG, Rhodes KV, Shofer FS, Hollander JE. ED crowding is associated with variable perceptions of care compromise. Acad Emerg Med. 2007;14(12):1176-81.

86. Sills MR, Fairclough D, Ranade D, Kahn MG. Emergency department crowding is associated with decreased quality of care for children with acute asthma. Ann Emerg Med. 2011;57(3):191-200 e1-7.

87. Higginson I, Kehoe A, Whyatt J, Smith JE. The 4-hour standard is a meaningful quality indicator: correlation of performance with emergency department crowding. Eur J Emerg Med. 2017;24(1):25-8.

88. Jo S, Kim K, Lee JH, Rhee JE, Kim YJ, Suh GJ, et al. Emergency department crowding is associated with 28-day mortality in community-acquired pneumonia patients. J Inf Secur. 2012;64(3):268-75. 
89. Michelson KA, Monuteaux MC, Stack AM, Bachur RG. Pediatric emergency department crowding is associated with a lower likelihood of hospital admission. Acad Emerg Med. 2012;19(7):816-20.

90. Chang AM, Cohen DJ, Lin A, Augustine J, Handel DA, Howell E, Kim H, Pines JM, Schuur JD, McConnell KJ, Sun BC. Hospital strategies for reducing emergency department crowding: a mixed-methods study. Annals of emergency medicine. 2018;71(4):497-505.

91. Ahn JY, Ryoo HW. New intervention model of regional transfer network system to alleviate crowding of regional emergency medical center. J Korean Med Sci. 2016;31(5):806-13.

92. Beck MJ, Okerblom D, Kumar A, Bandyopadhyay S, Scalzi LV. Lean intervention improves patient discharge times, improves emergency department throughput and reduces congestion. Hosp pract (1995). 2016;44(5):252-9.

93. Cha WC, Shin SD, Song KJ, Jung SK, Suh GJ. Effect of an independentcapacity protocol on overcrowding in an urban emergency department. Acad Emerg Med. 2009;16(12):1277-83.

94. Cha WC, Song KJ, Cho JS, Singer AJ, Shin SD. The long-term effect of an independent capacity protocol on emergency department length of stay: a before and after study. Yonsei Med J. 2015;56(5):1428-36.

95. Hoot NR, LeBlanc $\sqcup$, Jones I, Levin SR, Zhou C, Gadd CS, et al. Forecasting emergency department crowding: a discrete event simulation. Ann Emerg Med. 2008;52(2):116-25.

96. Cheng AH, Sutherland JM. British Columbia's pay-for-performance experiment: part of the solution to reduce emergency department crowding? Health Policy. 2013;113(1-2):86-92.

97. Kawano T, Nishiyama K, Hayashi H. Adding more junior residents may worsen emergency department crowding. PLoS One. 2014;9(11):e110801.

98. Huang EPC, Liu SSH, Fang CC, Chou HC, Wang CH, Yen ZS, et al. The impact of adding clinical assistants on patient waiting time in a crowded emergency department. Emerg Med J. 2013;30(12):1017-9.

99. Colak Oray N, Yanturali S, Atilla R, Ersoy G, Topacoglu H. A new model in reducing emergency department crowding: the electronic blockage system. Turkiye Acil Tip Dergisi. 2014;14(2):64-70.

100. Fieldston ES, Hall M, Shah SS, Hain PD, Sills MR, Slonim AD, et al. Addressing inpatient crowding by smoothing occupancy at children's hospitals. J Hosp Med. 2011:6(8):466-73.

101. Murphy SO, Barth BE, Carlton EF, Gleason M, Cannon CM. Does an ED flow coordinator improve patient throughput? J Emerg Nurs. 2014;40(6):605-12.

102. Scheuermeyer FX, Christenson J, Innes G, Boychuk B, Yu E, Grafstein E. Safety of assessment of patients with potential ischemic chest pain in an emergency department waiting room: a prospective comparative cohort study. Ann Emerg Med. 2010;56(5):455-62.

103. Richardson DB, Brockman K, Abigail A, Hollis GJ. Effects of a hospital-wide intervention on emergency department crowding and quality: a prospective study. Emerg Med Australas. 2017;29(4):415-20.

104. Geelhoed GC, de Klerk NH. Emergency department overcrowding, mortality and the 4-hour rule in Western Australia. Med J Aust. 2012;196:122-6.

105. Singer AJ, Viccellio P, Thode HC Jr, Bock JL, Henry MC. Introduction of a stat laboratory reduces emergency department length of stay. Acad Emerg Med. 2008;15(4):324-8.

106. Michael SS, Broach JP, Kotkowski KA, Brush DE, Volturo GA, MAJWJoEM R. Code Help: Can This Unique State Regulatory Intervention Improve Emergency Department Crowding? Western Journal of Emergency Medicine. 2018;19(3):501.

107. Martin N, Bergs J, Eerdekens D, Depaire B, Verelst S. Developing an emergency department crowding dashboard: A design science approach. Int Emerg Nurs. 2018;39:68-76.

108. Qureshi A, Smith A, Wright F, Brenneman F, Rizoli S, Hsieh T, et al. The impact of an acute care emergency surgical service on timely surgical decision-making and emergency department overcrowding. J Am Coll Surg. 2011;213(2):284-93.

109. Aksel G, Bildik F, Demircan A, Keles A, Kilicaslan I, Guler S, et al. Effects of fasttrack in a university emergency department through the National Emergency Department Overcrowding Study. J Pak Med Assoc. 2014;64(7):791-7.

110. Han JH, France DJ, Levin SR, Jones ID, Storrow AB, Aronsky D. The effect of physician triage on emergency department length of stay. J Emerg Med. 2010;39(2):227-33

111. Khanna S, Sier D, Boyle J, Zeitz K. Discharge timeliness and its impact on hospital crowding and emergency department flow performance. Emerg Med Australas. 2016:28(2):164-70.
112. Lee $H_{\text {, }}$ Chen $C T$, Lee $Y T$, Hsu YS, Lu CL, Huang HH, et al. A new strategy for emergency department crowding: high-turnover utility bed intervention. J Chin Med Assoc. 2017;80(5):297-302.

113. Roman CP, Poole SG, Dooley MJ, Smit de V, Mitra B. Implementation of hospital-wide reform at improving access and flow: impact on time to antibiotics in the emergency department. Emerg Med Australas. 2016; 28(2):133-7.

114. Sharieff GQ, Burnell L, Cantonis M, Norton V, Tovar J, Roberts K, et al. Improving emergency department time to provider, left-without-treatment rates, and average length of stay. J Emerg Med. 2013;45(3):426-32.

115. Schoenenberger LK, Bayer S, Ansah JP, Matchar DB, Mohanavalli RL, Lam SSW, et al. Emergency department crowding in Singapore: insights from a systems thinking approach. SAGE Open Med. 2016:4:1-10.

116. Crilly J, O'Dwyer J, Lind J, Tippett V, Thalib L, O'Dwyer M, et al. Impact of opening a new emergency department on healthcare service and patient outcomes: analyses based on linking ambulance, emergency and hospital databases. Intern Med J. 2013;43(12):1293-303.

117. Mumma BE, McCue JY, Li CS, Holmes JF. Effects of emergency department expansion on emergency department patient flow. Acad Emerg Med. 2014 21(5):504-9.

118. Haghighinejad HA, Kharazmi E, Hatam N, Yousefi S, Hesami SA, Danaei M, et al. Using queuing theory and simulation Modelling to reduce waiting times in an Iranian emergency department. Int J Community Based Nurs Midwifery. 2016:4(1):11-26.

119. Lee J, Greenspan PT, Israel E, Katz A, Fasano A, Kaafarani HM, Linov PL, Raja AS, Rao SK. Emergency department utilization report to decrease visits by pediatric gastroenterology patients. Pediatrics. 2016 Jul 1;138(1):e20153586.

120. Lee J, Israel E, Weinstein $H$, Kinane TB, Pasternack M, Linov P, Kaafarani HM, Greenspan P, Rao SK. Using physician-level emergency department utilization reports to address avoidable visits by patients managed by pediatric specialists. Hosp pediatr. 2017 Nov 1;7(11):686-91.

\section{Publisher's Note}

Springer Nature remains neutral with regard to jurisdictional claims in published maps and institutional affiliations.
Ready to submit your research? Choose BMC and benefit from:

- fast, convenient online submission

- thorough peer review by experienced researchers in your field

- rapid publication on acceptance

- support for research data, including large and complex data types

- gold Open Access which fosters wider collaboration and increased citations

- maximum visibility for your research: over $100 \mathrm{M}$ website views per year

At BMC, research is always in progress.

Learn more biomedcentral.com/submission 